\title{
Morbid risk for schizophrenia in first-degree relatives of people with frontotemporal dementia
}

Delphine Schoder, Didier Hannequin, Olivier Martinaud, Gaëlle Opolczynski, Lucie Guyant-Maréchal, Isabelle Le Ber and Dominique Campion

\section{Background}

Familial co-occurrence of frontotemporal dementia and schizophrenia has never been investigated.

\section{Aims}

To test the hypothesis that frontotemporal dementia and schizophrenia might have a common aetiology in some families in which both syndromes coexist (mixed families).

\section{Method}

The morbid risk for schizophrenia, calculated in first-degree relatives of 100 frontotemporal dementia probands, was compared with that calculated in first-degree relatives of 100 Alzheimer's disease probands. In mixed families, sequencing analysis of known frontotemporal dementia genes and detailed phenotype characterisation of individuals with frontotemporal dementia and schizophrenia were performed.

\section{Results}

The morbid risk for schizophrenia was significantly higher in relatives of frontotemporal dementia probands (1.35, s.e. $=0.45)$ than in relatives of Alzheimer's disease probands $(0.32$, s.e. $=0.22)$. Ten mixed families were characterised. In three of them a frontotemporal dementia causal mutation was identified that was present in individuals with schizophrenia. Several specific clinical features were noted in people with schizophrenia and frontotemporal dementia in mixed families.

\section{Conclusions}

Co-occurrence of schizophrenia and frontotemporal dementia could indicate, in some families, a common aetiology for both conditions.

\section{Declaration of interest} None.
Frontotemporal dementia, diagnosed according to the clinical and paraclinical criteria established by Neary et $a l,{ }^{1}$ and schizophrenia, defined on a syndromal basis by the DSM, are two neurobehavioral syndromes characterised by a profound alteration in personal and social conduct reflecting marked frontal dysfunction. However, specific features distinguish these two syndromes. First, clinically, age at onset for frontotemporal dementia is generally above age $45{ }^{2}$ whereas in most cases it is well below this age for schizophrenia. ${ }^{3}$ Shared symptoms of both syndromes include emotional blunting, disorganised behaviours and language disturbances. ${ }^{1,3,4}$ However, delusions and hallucinations, very common in schizophrenia, ${ }^{3}$ are rarely described in frontotemporal dementia, although a high rate of visual hallucinations has recently been reported in individuals with frontotemporal dementia and PGRN mutations. ${ }^{5}$ The course of both conditions also differs: frontotemporal dementia progresses in a constant way towards a decline, ${ }^{1,2}$ whereas the course is variable in schizophrenia. ${ }^{6}$ Second, structural imaging typically shows a marked frontotemporal atrophy in frontotemporal dementia, ${ }^{2}$ whereas in schizophrenia, the most consistent findings include ventricular enlargement and slight to moderate brain matter deficits in the superior temporal gyrus and medial temporal lobe structures. ${ }^{7}$ Functional imaging generally reveals a marked frontotemporal hypoperfusion in frontotemporal dementia. ${ }^{2}$ In schizophrenia, hypofrontality is not a well-replicated finding, however a metaanalysis has supported hypofrontality both at the resting state and when performing cognitive tasks involving the frontal cortex. ${ }^{8}$ Finally, on neuropathological grounds, frontotemporal dementia is characterised by massive neuronal loss, leading to microvacuolation of the cerebral cortex and astrocytic gliosis. ${ }^{9}$ At the subcellular level, although a subset of frontotemporal dementia lacks distinct histological features, in most cases specific lesions corresponding to different types of aggregates (hyperphosphorylated tau-positive neurofibrillary tangles or ubiquitinpositive inclusions containing TDP-43 protein) are found, which depend on the underlying genetic defect. ${ }^{9}$ In schizophrenia, neuropathological studies suggest a reduction in neuronal volume without cellular loss or intracellular inclusions and without gliosis. ${ }^{10}$ Despite these differences, the circumstantial observation of a few families in which both conditions coexist led us to hypothesise that the two syndromes might have in some cases a common aetiology. To test this hypothesis, three questions were addressed in this study. First, the morbid risk for schizophrenia and schizoaffective disorder, calculated in first-degree relatives of 100 frontotemporal dementia probands was compared with that calculated in a control sample of first-degree relatives of 100 Alzheimer's disease probands. Second, in families that included relatives with schizophrenia for which a causal mutation had been identified in the frontotemporal dementia proband, the segregation of this mutation was studied among relatives. Third, a detailed clinical, neuropsychological and neuroimaging characterisation of individuals with frontotemporal dementia and schizophrenia was undertaken in the ten mixed families in which both conditions co-occurred.

\section{Method}

\section{Ascertainment of probands}

Frontotemporal dementia probands, ascertained from consecutive consultations in the Department of Neurology of Rouen University Hospital between 2001 and 2007, were required to fulfil the Neary et al criteria for frontotemporal dementia. ${ }^{1}$ Alzheimer's disease probands used to establish a control group were sampled from the same department and met the National Institute of Neurological and Communicative Disorders and Stroke and the Alzheimer's Disease and Related Disorders Association (NINCDS-ADRDA) criteria for probable Alzheimer's disease. ${ }^{11}$ They formed a screened control group in which none of the Alzheimer's disease probands had schizophrenia or schizoaffective 
disorder according to DSM-III-R criteria. ${ }^{3}$ They were matched for age with frontotemporal dementia probands (64.1 years, s.d. $=7.6$ for frontotemporal dementia $v .66 .6$ years, s.d. $=9.5$ for Alzheimer's disease). All participants were Caucasian and living in the west of France. Investigations were performed with the written informed consent of participants according to protocols approved by the ethics committee of Paris-Necker Hospital.

\section{Information on relatives with schizophrenia}

The initial screening for first-degree relatives with schizophrenia or schizoaffective disorder was based on the family history method, which relies on the interview of one or more informants per family (usually the spouse or children of the participant). When alive, persons suspected to be presenting with such a disorder were then directly evaluated by the Schedule for Affective Disorders and Schizophrenia - Lifetime version (SADS-L) semistructured interview ${ }^{12}$ and their clinical records were reviewed to establish a diagnosis according to the DSM-III-R criteria. ${ }^{3}$ For deceased relatives, the diagnosis of schizophrenia was made retrospectively using medical records and by interview of family members. Best estimate diagnoses were made by the same two psychiatrists (D.S. and D.C.). Relatives fulfilling the diagnosis of schizophrenia or schizoaffective disorder were included in the morbid risk assessment. The same method was used to identify and characterise more distant relatives with schizophrenia of frontotemporal dementia probands that were included in the subsequent clinical and genetic studies.

\section{Calculation and statistical comparison of morbid risk}

For the calculation of the schizophrenia morbid risk in firstdegree relatives of frontotemporal dementia or Alzheimer's disease probands, we used the abridged Weinberg method. This method of age correction involves dividing the total number of affected first-degree relatives by the total number of first-degree relatives weighted by a factor depending on the age of the relatives. The age-adjusted weighting factor is defined according to the risk period for disease onset. It allows us to take into account that relatives did not provide the same information about their risk of receiving a diagnosis of schizophrenia or schizoaffective disorder, depending on whether they have not yet entered the risk period, whether they are currently within it or whether they have moved out of it. For participants under age 15 the weighting factor was 0 , between age 15 and 45 it was 0.5 and above age 45 it was 1 . In order to compare morbid risks between the two groups we used a $z$-test, modified for the comparison of morbid risks, as defined by Breborowicz et al. ${ }^{13}$ We performed this comparison at the alpha risk of $5 \%$.

\section{Mutation analysis}

Sequencing of three genes involved in familial forms of frontotemporal dementia (MAPT, VCP and PGRN) was conducted among frontotemporal dementia probands using previously described methods. ${ }^{14-16}$ When a mutation was identified in a family associating frontotemporal dementia and schizophrenia cases, segregation of this mutation was studied among individuals with schizophrenia.

\section{Characterisation of participants with frontotemporal dementia}

Behavioural and psychiatric symptoms of participants with frontotemporal dementia (probands and relatives) were characterised using items of the Frontal Behavioural Inventory
$(\mathrm{FBI})^{17}$ and the Neuropsychiatric Inventory (NPI) ${ }^{18}$ scales. These items were used to quantify the frequency of delusions, hallucinations, depression, euphoria, disinhibition, apathy and language reduction. The age at onset was defined as the age at which the first symptom appeared as reported by the informant. The neuropsychological evaluation included the Mini-Mental State Examination (MMSE), ${ }^{19}$ the Mattis Dementia Rating Scale $(\mathrm{MDRS})^{20}$ and the Frontal Assessment Battery (FAB). ${ }^{21}$ Participants with frontotemporal dementia underwent brain magnetic resonance imaging (MRI) or computed tomography (CT) scanning. Brain perfusion was evaluated with Tc-99m technetium ethyl cysteinate dimmer single-photon emission computed tomography (Tc-99m ECD SPECT).

\section{Characterisation of participants with schizophrenia}

A quantitative assessment of positive and negative symptoms of individuals with schizophrenia was conducted with the Positive and Negative Syndrome Scale (PANSS). ${ }^{22}$ The clinical interviews with participants were supplemented by consultation of their medical records. The response to antipsychotic treatment was assessed by the May and Dencker scale. ${ }^{23}$ The neuropsychological evaluation involved the MMSE, the MDRS, the FAB, the Wechsler Adult Intelligence Scale-III (WAIS-III), ${ }^{24}$ the clock-drawing, ${ }^{25}$ copy of the Rey-Osterrieth's complex figure, ${ }^{26}$ evaluation of oral naming, ${ }^{27}$ the Free and Cued Recall Test (FCRT), ${ }^{28}$ and the assessment of executive functions including the categorical and literal verbal fluency tasks in 2 minutes, ${ }^{29}$ parts $\mathrm{A}$ and $\mathrm{B}$ of the Trail Making Test (TMT A/B), ${ }^{30}$ the Stroop test ${ }^{31}$ and the Modified Card Sorting Test (MCST). ${ }^{32}$

The participants with schizophrenia entering the risk period for frontotemporal dementia received a more detailed evaluation, including, in addition to the psychiatric and neuropsychological assessments, a neurological examination and when possible brain imaging. Based on neuropsychological, clinical and imaging data, the possibility of a diagnosis change from schizophrenia or schizoaffective disorder to frontotemporal dementia was evaluated for participants with schizophrenia aged 45 and above.

\section{Results}

\section{Morbid risk for schizophrenia in first-degree relatives of frontotemporal dementia and Alzheimer's disease probands}

Among the 121 probands fulfilling the criteria for frontotemporal dementia, ${ }^{1} 21$ (17.3\%) were excluded due to lack of reliable familial information. We thus included 100 frontotemporal dementia probands, 57 women and 43 men, 60 familial v. 40 sporadic cases. Five probands bore a PGRN mutation, three a $V C P$ mutation and two a MAPT mutation. The mean age at onset for the 100 frontotemporal dementia probands was 60.4 years (s.d. $=7.8$, range $43-80$ ). The mean disease duration at inclusion was 4 years $($ s.d. $=2.5$, range $0-14)$. These probands had 819 first-degree relatives, including 9 individuals, from 7 mixed families, who were diagnosed with schizophrenia or schizoaffective disorder. Characterisation of the participants with schizophrenia or schizoaffective disorder is summarised in Table 1. Mean age at onset for the nine individuals with schizophrenia included in the morbid risk assessment was 29.5 years (s.d. $=7.5$, range 16-39), mean duration of illness was 17 years (s.d. $=10.6$, range 7-40). Three people with schizophrenia were deceased at inclusion. They had no autopsy. The age-adjusted number of relatives was $n=665.5$. The morbid risk for schizophrenia and schizoaffective disorder in first-degree relatives of frontotemporal dementia probands was 1.35 (s.e. $=0.45$ ). 


\begin{tabular}{|c|c|c|c|c|c|c|}
\hline \multirow[b]{2}{*}{ Participant } & \multirow[b]{2}{*}{ Age, years } & \multirow[b]{2}{*}{$\begin{array}{l}\text { Age at onset, } \\
\text { years }\end{array}$} & \multirow[b]{2}{*}{$\begin{array}{c}\text { Disease duration, } \\
\text { years }\end{array}$} & \multicolumn{2}{|c|}{ Clinical assessment } & \multirow[b]{2}{*}{ Diagnosis, DSM-III-R criteria } \\
\hline & & & & $\begin{array}{c}\text { Clinical interview } \\
\qquad(n=11)\end{array}$ & $\begin{array}{l}\text { Medical records } \\
\quad(n=20)\end{array}$ & \\
\hline F1. III-1 & 60 & 31 & 29 & Yes & Yes & Undifferentiated schizophrenia \\
\hline F1. III-2 & 59 & 15 & 44 & Yes & Yes & Disorganised schizophrenia \\
\hline F1. IV-6 & 28 & 24 & 4 & Yes & Yes & Undifferentiated schizophrenia \\
\hline F2. $\| 1 \mid-1^{a}$ & 47 & 39 & 8 & No (refusal) & Yes & Paranoid schizophrenia \\
\hline F2. III-2a & 46 & 37 & 9 & No (refusal) & Yes & Undifferentiated schizophrenia \\
\hline F3. $11-4^{a}$ & $61^{\mathrm{b}}$ & 34 & 27 & No (deceased) & Yes & Undifferentiated schizophrenia \\
\hline F4. $\| 1-2^{a}$ & 56 & 16 & 40 & Yes & Yes & Schizoaffective disorder \\
\hline F4. III-3 $3^{\mathrm{a}}$ & 31 & 24 & 7 & Yes & Yes & Paranoid schizophrenia \\
\hline F4. III-4 & $22^{b}$ & 19 & 3 & No (deceased) & Yes & Paranoid schizophrenia \\
\hline F4. III-5 & 22 & 19 & 3 & Yes & Yes & Paranoid schizophrenia \\
\hline F5. $1111-3^{\mathrm{a}}$ & $48^{\mathrm{b}}$ & 30 & 18 & No (deceased) & Yes & Schizoaffective disorder \\
\hline F5. III-4 & 77 & 38 & 39 & Yes & Yes & Paranoid schizophrenia \\
\hline F5. IV-4 & 42 & 20 & 22 & No (refusal) & Yes & Schizoaffective disorder \\
\hline F6. $111-12^{a}$ & 38 & 23 & 15 & Yes & Yes & Paranoid schizophrenia \\
\hline F7. IV-2 ${ }^{\mathrm{a}}$ & 44 & 28 & 16 & Yes & Yes & Undifferentiated schizophrenia \\
\hline F7. IV-5 & 59 & 20 & 39 & Yes & Yes & Disorganised schizophrenia \\
\hline F8. III-1 & 50 & 23 & 27 & Yes & Yes & Disorganised schizophrenia \\
\hline F8. IV-2 & $27^{\mathrm{b}}$ & 19 & 8 & No (deceased) & Yes & Paranoid schizophrenia \\
\hline F9. III-22 & 35 & 25 & 10 & No (refusal) & Yes & Paranoid schizophrenia \\
\hline F10. III-9 & $48^{b}$ & 35 & 13 & No (deceased) & Yes & Undifferentiated schizophrenia \\
\hline
\end{tabular}

The control group included 100 Alzheimer's disease probands (61 women and 39 men, 52 familial $v .48$ sporadic cases). The mean age at onset in the Alzheimer's disease probands group was 62.5 years $($ s.d. $=9.4)$ and the mean disease duration at inclusion was 4.3 years $($ s.d. $=2.3)$. These probands had 741 first-degree relatives, including two participants, from two families, who were diagnosed with schizophrenia (age at onset 17 and 26 years). The age-adjusted number of relatives was $n=627.5$. The age distributions were relatively similar in both groups of relatives (frontotemporal dementia and Alzheimer's disease). The morbid risk for schizophrenia and schizoaffective disorder in first-degree relatives of Alzheimer's disease probands was 0.32 (s.e. $=0.22$ ).

Thus, the morbid risk for schizophrenia and schizoaffective disorder was significantly higher in first-degree relatives of frontotemporal dementia probands than in first-degree relatives of Alzheimer's disease probands $(z=2, P=0.05)$.

\section{Genetic study}

When including three additional families in which individuals with schizophrenia were identified in more distant relatives of a frontotemporal dementia proband, a total of ten mixed families were characterised. Causal frontotemporal dementia mutations were identified in three of these ten mixed families (Fig. 1).

In family F8 (not included for morbid risk assessment), a PGRN mutation (p.Met1? $)^{5}$ was found in two participants with frontotemporal dementia (the index case III-4 and III-5) and in a 50-year-old patient with schizophrenia (III-1). Another individual with schizophrenia (IV-2) died by suicide at the age of 27 years without having been genetically analysed.

In family F9 (not included for morbid risk assessment), a VCP mutation (p.Arg93Cys) ${ }^{15}$ was found in all participants with frontotemporal dementia who had been genotyped (II-1, II-3, II-4, III-1), but also in three still asymptomatic individuals (II-5,
III-14, III-15). This mutation was also identified in the individual III-22, aged 35 years, who had schizophrenia. However, it was not found in participant IV-4, who had bipolar disorder.

In family F10, a VCP mutation (p.Arg155Cys) ${ }^{15}$ was found in all participants with frontotemporal dementia who had been genotyped (II-5, II-6, II-8, III-36). It was also identified in four family members without frontotemporal dementia (II-12, III-31, III-37, III-38, IV-1), but with inclusion body myopathy caused by the VCP mutation. Finally, the mutation was also present in individual III-9, who had schizophrenia and inclusion body myopathy and who died by suicide at the age of 48 years.

Thus, in mixed families in which a frontotemporal dementia causal mutation has been identified, the three individuals with schizophrenia all bore this mutation.

\section{Characterisation of participants with frontotemporal dementia in mixed families}

A total number of 22 individuals fulfilled the Neary et al criteria ${ }^{1}$ for frontotemporal dementia in the 10 mixed families. The mean age at onset for frontotemporal dementia in these 22 individuals $(57.5$ years, s.d. $=7.5)$ was not different from that observed in the other 90 frontotemporal dementia probands (60.4 years, s.d. =7.9) (Mann-Whitney $U$-test, $P=0.17)$. Only 19 participants with frontotemporal dementia for whom sufficient clinical data were available (18 of them directly examined and 17 neuropsychologically evaluated) were included in the clinical study. Clinical characteristics and neuropsychological data of these 19 individuals with frontotemporal dementia are reported in online Table DS1.

With regard to psychotic symptoms, among the 19 participants with frontotemporal dementia evaluated, 5 experienced at least one delusional episode during the course of their disease (26.3\%), 4 had auditory hallucinations (21\%) and 1 had visual hallucinations (5.3\%). Delusions and auditory hallucinations were significantly more frequent in these participants than in the group 
(a)

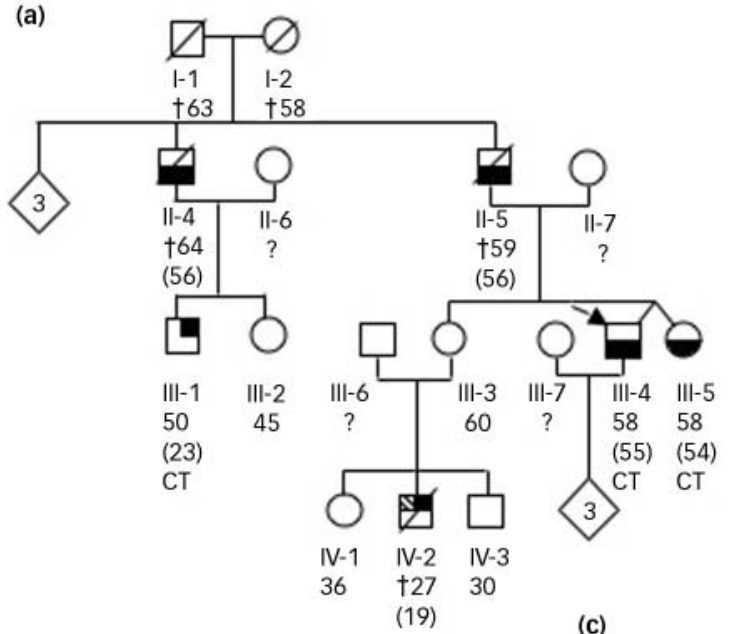

(b)

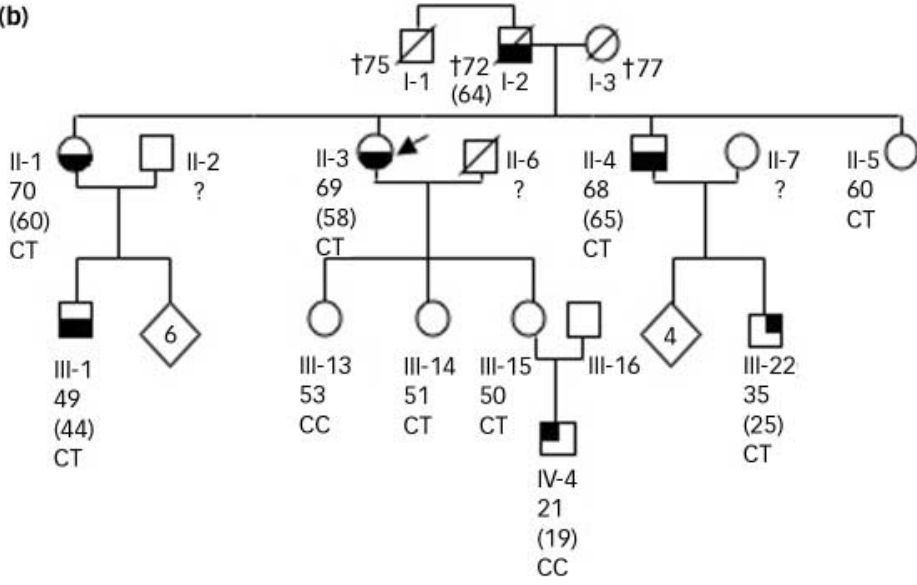

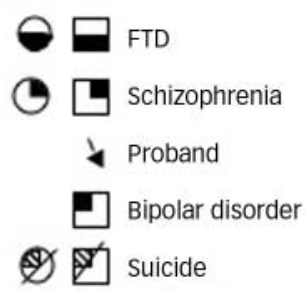

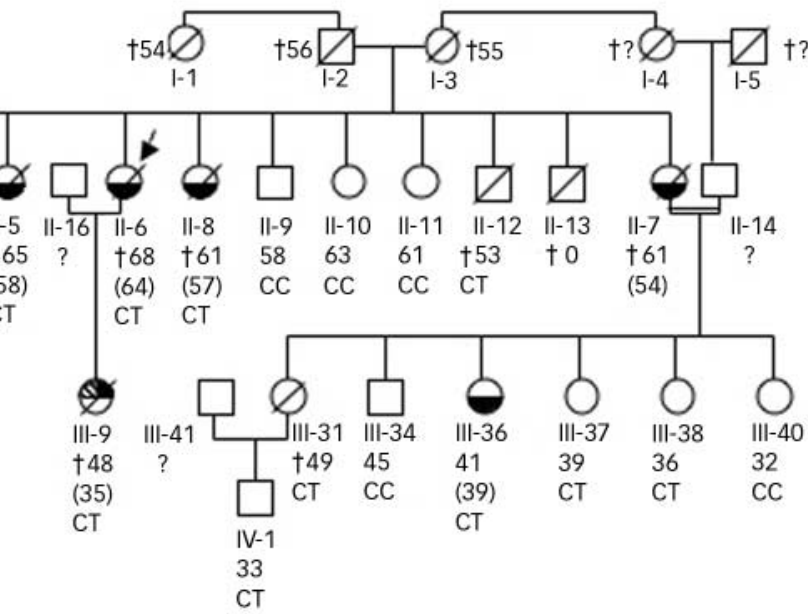

Fig. 1 Reduced pedigrees of families with PGRN (a) or VCP mutations (b) and (c). (a) Family F8, PGRN p.Met1? mutation; (b) Family F9, VCP p.Arg93Cys mutation; (c) Family F10, VCP p.Arg155Cys mutation.

Subscript numbers refer to current age, age at death ' $t$ ' or age at onset ' ()$^{\prime}$ in years. For families with $V C P$ mutations, myopathy and bone disease are not reported in pedigrees. Genotypes are indicated. C, wild type allele; T, mutant allele.

of other 90 frontotemporal dementia probands (Fisher, $P=0.05$ and $P=0.02$ respectively), whereas no significant differences were found between both groups with respect to the frequency of visual hallucinations and mood symptoms (euphoria, depression).

\section{Characterisation of participants with schizophrenia}

In the 10 mixed families, 20 individuals with schizophrenia were diagnosed among first-, second- and third-degree relatives of frontotemporal dementia probands (Table 1). In six families, more than one relative with schizophrenia was present. Among the 20 participants with schizophrenia, $5(25 \%)$ died before the present study. Of those alive, four $(26.7 \%)$ refused to participate in psychiatric interviews. We were however able to examine the clinical records of all participants. Items of the SADS- $\mathrm{L}^{12}$ and the May and Dencker scale ${ }^{23}$ were quoted from the clinical interview and the consultation of medical records for 11 individuals, and from medical records only for the remaining 9 people. We were able to achieve 11 clinical evaluations by the PANSS. ${ }^{22}$ A neuropsychological evaluation was partially or totally achieved for 12 participants with schizophrenia.

Among the 20 participants with schizophrenia, 3 had a lifetime diagnosis of schizoaffective disorder (15\%), 3 had a disorganised type of schizophrenia (15\%), 8 had a paranoid type $(40 \%)$ and 6 had an undifferentiated type (30\%). According to the PANSS classification ${ }^{22}$ we established, from the score on the composite scale, 7 negative subtypes $(63.6 \%)$ and 4 positive subtypes (36.4\%) out of 11 individuals evaluated. Response to antipsychotic treatment among the 20 people with schizophrenia was good since $17(85 \%)$ were 'treatment responding' (score $\leqslant 4)$ and only 3 (15\%) (not included in the morbid risk assessment) were considered as 'treatment refractory' (scores 5-6). Regarding associated psychiatric symptoms among the 20 participants with schizophrenia, it is interesting to note the high frequency of mood disorders. Indeed, in addition to the three participants with schizoaffective disorder, eight others with schizophrenia had experienced at least one major depressive episode requiring antidepressant treatment. A high frequency of suicidal behaviours among individuals with schizophrenia in these mixed families is also noteworthy. Indeed, $70 \%$ of them had attempted suicide at least once, and $15 \%$ died by suicide. The results of the neuropsychological evaluation obtained from 12 participants with schizophrenia are reported in online Table DS2. In young participants (under age 45), of whom six were tested, three displayed no cognitive impairment and three showed memory difficulties associated with executive functions deficit.

\section{Possible diagnosis change from schizophrenia to frontotemporal dementia during the course of schizophrenia}

Among the 20 participants with schizophrenia, 11 were 45 years old and above, 8 of whom were clinically and 6 neuropsychologically 
evaluated (Table 2). Focusing on these older participants, a nonspecific demented evolution was present in two of them. It was evidenced by clinical and neuropsychological data in participant F5. III-4 and by clinical and imaging data in participant F1. III-2, who was too heavily deteriorated for a neuropsychological assessment. A third participant (F8. III-1), with marked negative symptoms, had a neuropsychological profile of dementia with prominent executive dysfunction and a normal brain CT scan. A fourth individual (F10. III-9), although having minimal executive deficit and frontal bilateral hypoperfusion on SPECT at the age of 47 years, did not fulfil sufficient clinical criteria for the diagnosis of frontotemporal dementia. Only one of these four participants with possible diagnosis change was a first-degree relative of a frontotemporal dementia proband and therefore only one had been included in the schizophrenia morbid risk assessment.

\section{Discussion}

\section{Familial co-occurrence of frontotemporal dementia and schizophrenia: more than a coincidence?}

The prevalence of frontotemporal dementia is currently estimated to be between 3.6 and 15 cases per $100000,{ }^{2}$ whereas the prevalence of schizophrenia is usually estimated to be between 500 and 1000 cases per 100000 . Thus, because of the high prevalence of schizophrenia in the general population, the co-occurrence of schizophrenia and frontotemporal dementia could have been fortuitous in some families. Alternatively, such an association could suggest a common aetiology. We bring two arguments in favour of this hypothesis: the morbid risk for schizophrenia is significantly increased in first-degree relatives of

Table 2 Clinical, neuropsychological and neuroimaging characteristics of participants with schizophrenia aged 45 and above

\begin{tabular}{|c|c|c|c|c|c|c|}
\hline Participant & $\begin{array}{l}\text { Age, } \\
\text { years }\end{array}$ & $\begin{array}{l}\text { Disease } \\
\text { duration, } \\
\text { years }\end{array}$ & $\begin{array}{l}\text { Progression of symptoms during } \\
\text { the course of the disease }\end{array}$ & $\begin{array}{l}\text { Neurological } \\
\text { examination }\end{array}$ & $\begin{array}{l}\text { Brain } \\
\text { imagery }\end{array}$ & $\begin{array}{l}\text { Neuropsychological } \\
\text { evaluation }\end{array}$ \\
\hline F1. III-1 & 60 & 29 & $\begin{array}{l}\text { Verbal disinhibition, reduction of } \\
\text { spontaneous language, ritualistic } \\
\text { behaviours, no recent change in } \\
\text { negative symptoms (apathy, social } \\
\text { withdrawal, emotional blunting) }\end{array}$ & $\begin{array}{l}\text { Parkinsonian syndrome } \\
\text { (antipsychotic treatment), } \\
\text { no primary reflexes } \\
\text { (grasping, sucking) }\end{array}$ & Refusal & Refusal \\
\hline F1. III-2 & 59 & 44 & $\begin{array}{l}\text { Reduction in activities, loss of interest, } \\
\text { loss of initiative, apathy, neglect of } \\
\text { hygiene, loss of independence in } \\
\text { activities of daily living, urinary incontinence, } \\
\text { disinhibition, aggressiveness, reduction } \\
\text { of spontaneous language, verbal } \\
\text { stereotypies. Institutionalisation }\end{array}$ & $\begin{array}{l}\text { Opposition, agitation, no } \\
\text { primary reflexes }\end{array}$ & $\begin{array}{l}\text { CT scan: } \\
\text { significant } \\
\text { cortical and } \\
\text { subcortical } \\
\text { atrophy }\end{array}$ & Not possible \\
\hline F2. III-2 ${ }^{a}$ & 46 & 9 & $\begin{array}{l}\text { No recent progression of behavioural } \\
\text { symptomatology. Preservation of } \\
\text { independence in activities of daily living }\end{array}$ & Refusal & Refusal & No cognitive deficit \\
\hline F4. $11-2^{a}$ & 56 & 40 & $\begin{array}{l}\text { No recent progression of behavioural } \\
\text { symptomatology. Preservation of } \\
\text { independence in activities of daily living }\end{array}$ & $\begin{array}{l}\text { Mild Parkinsonian syndrome } \\
\text { (antipsychotic treatment), } \\
\text { no primary reflexes }\end{array}$ & $\begin{array}{l}\text { CT scan: } \\
\text { normal }\end{array}$ & $\begin{array}{l}\text { Memory deficit, executive } \\
\text { dysfunction }\end{array}$ \\
\hline F5. III-4 & 77 & 39 & $\begin{array}{l}\text { Reduction of spontaneous language, social } \\
\text { withdrawal, apathy, ritualistic behaviours, } \\
\text { reduction in activities, loss of initiative, } \\
\text { loss of independence in activities of daily } \\
\text { living (professional home help), legal } \\
\text { guardianship because of excessive } \\
\text { spending and unsanitary house }\end{array}$ & $\begin{array}{l}\text { Parkinsonian syndrome } \\
\text { (antipsychotic treatment), } \\
\text { imitation behaviour, } \\
\text { perseverative behaviours, } \\
\text { poverty of speech }\end{array}$ & $\begin{array}{l}\text { CT scan: } \\
\text { cortical } \\
\text { atrophy } \\
\text { consistent } \\
\text { with her age }\end{array}$ & $\begin{array}{l}\text { Severe deterioration of } \\
\text { overall cognitive functions } \\
\text { Consistent with dementia }\end{array}$ \\
\hline F7. IV-5 & 59 & 39 & $\begin{array}{l}\text { No recent change in negative symptoms } \\
\text { (apathy, social withdrawal, emotional } \\
\text { blunting, poverty of speech, avolition) } \\
\text { Institutionalisation }\end{array}$ & $\begin{array}{l}\text { Parkinsonian syndrome } \\
\text { (antipsychotic treatment), } \\
\text { no primary reflexes }\end{array}$ & Not possible & $\begin{array}{l}\text { Frontal Assessment } \\
\text { Battery score }=9 \text {; other } \\
\text { neuropsychological tests } \\
\text { not possible }\end{array}$ \\
\hline F8. III-1 & 50 & 27 & $\begin{array}{l}\text { Reduction of spontaneous language, } \\
\text { reduction in activities, loss of interest, } \\
\text { loss of initiative, apathy, lack of projects, } \\
\text { social withdrawal, ritualistic behaviours, } \\
\text { verbal and behavioural stereotypies, } \\
\text { perseverations, time disorientation about } \\
\text { his biography } \\
\text { Long-term hospitalisation }\end{array}$ & $\begin{array}{l}\text { Stereotyped behaviours, } \\
\text { poverty of speech, no } \\
\text { primary reflexes }\end{array}$ & $\begin{array}{l}\text { CT scan: } \\
\text { normal }\end{array}$ & $\begin{array}{l}\text { Low full-scale IQ score }=47 \\
\text { (Wechsler Adult Intelligence } \\
\text { Scale-III) inconsistent with } \\
\text { his educational level and } \\
\text { previous evaluation } \\
\text { (Wechsler Adult Intelligence } \\
\text { Scale score = } 75 \text { when he } \\
\text { was } 30 \text { years old), memory } \\
\text { deficit, executive dysfunction } \\
\text { Consistent with dementia }\end{array}$ \\
\hline F10. III-9a & $48^{\mathrm{b}}$ & 13 & $\begin{array}{l}\text { Reduction in activities, inability to work } \\
8 \text { years before her death, preservation } \\
\text { of independence in activities of daily living } \\
\text { Death by suicide at } 48\end{array}$ & $\begin{array}{l}\text { Muscle weakness, } \\
\text { no primary reflexes }\end{array}$ & $\begin{array}{l}\text { MRI: normal } \\
\text { SPECT: } \\
\text { bilateral } \\
\text { frontal } \\
\text { hypoperfusion }\end{array}$ & $\begin{array}{l}\text { Low full-scale IQ score }=63 \\
\text { (Wechsler Adult Intelligence } \\
\text { Scale-III), mild executive } \\
\text { deficit }\end{array}$ \\
\hline
\end{tabular}


people with frontotemporal dementia compared with that found in first-degree relatives of people with Alzheimer's disease; and in three families with an identified frontotemporal dementia mutation, there is a co-segregation between the mutation and schizophrenia.

\section{Differential diagnosis between schizophrenia and frontotemporal dementia}

It could be argued that relatives with schizophrenia might in fact be misdiagnosed and have frontotemporal dementia. Indeed, since frontotemporal dementia and schizophrenia share many clinical features, especially related to negative symptoms (e.g. blunted affects, apathy, social withdrawal), ${ }^{1,3,4}$ the distinction between each condition is not straightforward. However, the hypothesis that these relatives have misdiagnosed frontotemporal dementia is unlikely since, first, the diagnosis of schizophrenia was given in young individuals (mean age at onset 29.5 years) and it remained stable for a mean period of 17 years. The oldest age at onset was 39. Conversely, it should be stressed that the diagnosis of frontotemporal dementia, although possible, is very rare before age 40. For example, the youngest age at onset among our 100 frontotemporal dementia probands was 43 years. In the French frontotemporal dementia database, including 252 patients ascertained from consecutive consultations in several hospitals, only 6 patients $(2 \%)$ had an age at onset before age 40 (details available from the author on request). Second, during the course of their disease, all participants with schizophrenia included in the morbid risk assessment had experienced marked positive symptoms (hallucinations, delusions), which are not common in frontotemporal dementia. ${ }^{2,4}$ By contrast, none of them exhibited disinhibition, antisocial behaviour, overeating, repetitive motor behaviours, mutism or incontinence, which are key features of frontotemporal dementia. Third, these nine people with schizophrenia were good responders to antipsychotic treatments, whereas these drugs are not reported to be of great efficacy in frontotemporal dementia.

\section{Implication of genetic findings}

Although a genetic component is described in both frontotemporal dementia and schizophrenia, different modes of inheritance have been identified in these conditions up to now. Regarding frontotemporal dementia, $30-40 \%$ of cases are consistent with an autosomal dominant inheritance. ${ }^{33}$ There is a significant genetic heterogeneity since four genes involved in these mendelian forms have so far been identified (MAPT, VCP, PGRN and CHMP2B), and other loci have been mapped. ${ }^{34}$ By contrast, a complex mode of inheritance involving interactions between different common DNA polymorphisms is generally assumed in schizophrenia albeit no susceptibility gene is currently identified with certainty. ${ }^{35}$ In the present study we have documented the occurrence of PGRN and VCP frontotemporal dementia causal mutations in three young people with schizophrenia. Since the submission of this manuscript, a report has been published describing another mixed family in which a Progranulin $(P G R N)$ mutation was identified both in one individual with frontotemporal dementia and one with schizophrenia. ${ }^{36}$ If these findings are not fortuitous, they imply that an alteration of frontotemporal dementia genes may also cause a schizophrenia phenotype. Assessing the presence of such rare highly penetrant mutations in large cohorts of people with schizophrenia would require a huge sequencing task. Recently, however, new whole genome scanning methods have made it possible to easily characterise many rare DNA rearrangements called copy number variants that are absent or present at very low frequency in controls and enriched in individuals with schizophrenia. They can either be transmitted or occur de novo. Since copy number variants findings provide strong evidence that highly penetrant monogenic forms of schizophrenia do exist, ${ }^{37}$ it remains to be determined whether some of the major genes targeted by these copy number variants in schizophrenia may also be affected by structural variations in frontotemporal dementia and vice versa. Supporting this latter hypothesis, we have recently identified during a copy number variant survey of psychiatric patients a MAPT gene duplication in an individual with schizophrenia (current age 54 years, age at onset 22 years). ${ }^{38}$

\section{Clinical particularities of participants with schizophrenia and frontotemporal dementia in mixed families}

We next investigated whether specific clinical forms of schizophrenia or frontotemporal dementia were present in mixed families. Regarding participants with schizophrenia, we found high frequencies of associated mood disorders (55\% of major depressive disorder and $15 \%$ of mania or hypomania), suicide attempts (70\%) and suicides (15\%). According to recent surveys, the percentage of individuals with schizophrenia who will make at least one suicide attempt in their lifetime has been estimated to be between 25 and $50 \%,{ }^{39}$ and the prevalence rate of suicides over an entire life has been estimated at $4.9 \%{ }^{40}$ Regarding individuals with frontotemporal dementia, the frequencies of delusions and auditory hallucinations in the 19 participants with frontotemporal dementia from mixed families $(26.3 \%$ had delusions, $21 \%$ had auditory hallucinations) were significantly higher than in the group of other 90 frontotemporal dementia probands. In addition, it can be noted that these frequencies are higher than those reported in the study of Mendez et al (2.3\% of 86 people with frontotemporal dementia had delusions and $0 \%$ had hallucinations). ${ }^{41}$

\section{Frontotemporal dementia and schizophrenia: single age-dependant continuum or phenotypic variable expression?}

We finally sought to establish if schizophrenia and frontotemporal dementia could be included in a single age-dependant continuum in some individuals. We did not find enough evidence to allow a diagnosis of frontotemporal dementia among eight participants with schizophrenia aged 45 and above who have been examined. Two of these individuals had a severe dementia with an unspecific profile at examination, and in two others we did not have sufficient evidence for a diagnosis of frontotemporal dementia, although a gradual decline in cognitive functions was reported. Several longitudinal studies have established that a subset of middle-aged and elderly people with schizophrenia display a marked decline in gross measures of cognitive status. ${ }^{42}$ Although the dementia found in some people with schizophrenia has been described as having a neuropsychological and functional neuroimaging profile similar to that of frontotemporal dementia, ${ }^{43}$ this issue remains insufficiently explored and warrants further investigations. Several cases of early adulthood schizophrenic syndrome prodromal of frontotemporal dementia, one of them being neuropathologically consistent with a diagnosis of Pick disease, have been described. ${ }^{44-47}$ Interestingly, a recent study including clinicopathological series and a literature review, has demonstrated that individuals with young-onset frontotemporal dementia may be diagnosed with schizophrenialike psychosis years before the dementia diagnosis is made ${ }^{47}$ At the present time, we cannot substantiate the hypothesis of a single age-dependent continuum between schizophrenia and frontotemporal dementia in the elderly participants of our families. We favour at the moment the less stringent hypothesis of the 
phenotypic variable expression (schizophrenia or frontotemporal dementia) of single genetic alterations. Since frontotemporal dementia is caused by mutations in genes belonging to well-defined biological pathways, our data, considered together, suggest that an alteration in these pathways could cause early adulthood subtle neuronal defects (whose clinical consequence might be a schizophrenic syndrome) in some individuals, and in others late adulthood massive neuronal losses in frontotemporal cortex leading to a frontotemporal dementia syndrome.

\section{Study limitations and future prospects}

The question can be raised as to whether a control group including relatives of Alzheimer's disease probands is an appropriate control group. To address this issue we have examined whether the morbid risk for schizophrenia in our control group was similar to that found in other control groups ascertained in different populations by using the same methods (i.e. inclusion of selected control probands free of schizophrenia-associated symptoms, diagnosis based on operational criteria such as DSM, structured interviews, best estimate diagnoses by two psychiatrists, age correction with the Weinberg or Stromgren method). Two reference studies aimed at studying the familial aggregation of schizophrenia fulfil these criteria. ${ }^{48,49}$ Both studies relied on direct interview of a large proportion of relatives, a procedure that is likely to yield a slightly better sensitivity for diagnosing schizophrenia in relatives than the family history method used in our work. In these studies, the morbid risk for schizophrenia in controls was $0.2($ s.e. $=0.2)$ and 0.6 respectively. These values can be compared with the $0.32($ s.e. $=0.22)$ value reported in the present study. In the 'Iowa 500' study, ${ }^{48}$ control probands $(n=318)$ were surgical patients, whereas in the Baron et al study, ${ }^{49}$ controls $(n=90)$ were acquaintances of well siblings of probands with schizophrenia. In both studies, as well as in our study, all control probands were screened to eliminate individuals with schizophrenia. We conclude that our results are consistent with those of other reports in which the control group was ascertained in a similar way as ours. However, our sample size remains limited, the statistical significance of our morbid risk comparison is modest, and these results should therefore be confirmed in other studies using a control group ascertained from a different population (e.g. surgical patients). Similarly, the co-segregation data between frontotemporal dementia mutations and schizophrenia are based on a few individuals and should be replicated in additional families. These findings, as well as the recent report of Velakoulis et $a l,{ }^{47}$ yield clinical implications and are relevant to both neurologists and psychiatrists. They point out the importance of a familial investigation for each person with schizophrenia or frontotemporal dementia, as well as a detailed clinical and paraclinical assessment of these individuals, focusing in particular on early symptoms in people with frontotemporal dementia and on the clinical course of those with schizophrenia.

Delphine Schoder, MD, INSERM U614, University of Medicine, Rouen, and
Department of Research, Rouvray PSychiatric Hospital, Sotteville-les-Rouen;
Didier Hannequin, MD, INSERM U614, University of Medicine, Rouen, and
Department of Neurology, Rouen University Hospital; Olivier Martinaud, MD,
Department of Neurology, Rouen University Hospital; Gaëlle Opolczynski, MPsych,
Department of Research, Rouvray Psychiatric Hospital, Sotteville-les-Rouen;
Lucie Guyant-Maréchal, MD, INSERM U614, University of Medicine, Rouen, and
Department of Neurology, Rouen University Hospital; Isabelle Le Ber, MD, PhD,
INSERM U679, AP-HP, Pitié-Salpêtrière Hospital, Paris; Dominique Campion, MD,
PhD, INSERM U614, University of Medicine, Rouen, and Department of Research,
Rouvray Psychiatric Hospital, Sotteville-les-Rouen, France

Correspondence: Dominique Campion, INSERM U614, University of Medicine 22 Boulevard Gambetta, 76000 Rouen, France. Email: Dominique.Campion@ univ-rouen.fr

First received 29 May 2009, final revision 9 Mar 2010, accepted 18 Mar 2010

\section{Acknowledgements}

We acknowledge Jacqueline Bou for genotyping of patients and all our colleagues who helped to contact patients.

\section{References}

1 Neary D, Snowden JS, Gustafson L, Passant U, Stuss D, Black S, et al. Frontotemporal lobar degeneration: a consensus on clinical diagnostic criteria. Neurology 1998; 51: 1546-54.

2 Neary D, Snowden J, Mann D. Frontotemporal dementia. Lancet Neurol 2005; 4: 771-80.

3 American Psychiatric Association. Diagnostic and Statistical Manual of Mental Disorders (3rd edn, revised) (DSM-III-R). APA, 1987.

4 Le Ber I, Guedj E, Gabelle A, Verpillat P, Volteau M, Thomas-Anterion C, et al. Demographic, neurological and behavioural characteristics and brain perfusion SPECT in frontal variant of frontotemporal dementia. Brain 2006; 129: $3051-65$

5 Le Ber I, Camuzat A, Hannequin D, Pasquier F, Guedj E, Rovelet-Lecrux A, et al. Phenotype variability in progranulin mutation carriers: a clinical, neuropsychological, imaging and genetic study. Brain 2008; 131: 732-46.

6 Tsuang MT, Woolson RF, Fleming JA. Long-term outcome of major psychoses. I. Schizophrenia and affective disorders compared with psychiatrically symptom-free surgical conditions. Arch Gen Psychiatry 1979; 36: 1295-301.

7 Shenton ME, Dickey CC, Frumin M, McCarley RW. A review of MRI findings in schizophrenia. Schizophr Res 2001; 49: 1-52.

8 Hill K, Mann L, Laws KR, Stephenson CM, Nimmo-Smith I, McKenna PJ. Hypofrontality in schizophrenia: a meta-analysis of functional imaging studies. Acta Psychiatr Scand 2004; 110: 243-56.

9 Cairns NJ, Bigio EH, Mackenzie IR, Neumann M, Lee VM, Hatanpaa KJ, et al. Neuropathologic diagnostic and nosologic criteria for frontotemporal lobar degeneration: consensus of the Consortium for Frontotemporal Lobar Degeneration. Acta Neuropathol 2007; 114: 5-22.

10 Harrison PJ. The neuropathology of schizophrenia. A critical review of the data and their interpretation. Brain 1999; 122: 593-624.

11 McKhann G, Drachman D, Folstein M, Katzman R, Price D, Stadlan EM Clinical diagnosis of Alzheimer's disease: report of the NINCDS-ADRDA Work Group under the auspices of Department of Health and Human Services Task Force on Alzheimer's Disease. Neurology 1984; 34: 939-44.

12 Mannuzza S, Fyer A, Klein D. Schedule for Affective Disorders and Schizophrenia, Lifetime Version. Traduction et adaptation française (trans M Leboyer). Doin éditeurs, 1985.

13 Breborowicz G, Trzebiatowska-Trzeciak O. A method for testing differences in morbidity risk for affective psychoses. Acta Psychiatr Scand 1976; 54: 353-8.

14 Dumanchin $C$, Camuzat $A$, Campion D, verpillat $P$, Hannequin D, Dubois $B$, et al. Segregation of a missense mutation in the microtubule-associated protein tau gene with familial frontotemporal dementia and parkinsonism. Hum Mol Genet 1998; 7: 1825-9.

15 Guyant-Marechal L, Laquerriere A, Duyckaerts C, Dumanchin C, Bou J, Dugny $F$, et al. Valosin-containing protein gene mutations: clinical and neuropathologic features. Neurology 2006; 67: 644-51.

16 Le Ber I, van der Zee J, Hannequin D, Gijselinck I, Campion D, Puel M, et al. Progranulin null mutations in both sporadic and familial frontotemporal dementia. Hum Mutat 2007; 28: 846-55.

17 Kertesz A, Davidson W, Fox H. Frontal behavioral inventory: diagnostic criteria for frontal lobe dementia. Can J Neurol Sci 1997; 24: 29-36.

18 Cummings JL, Mega M, Gray K, Rosenberg-Thompson S, Carusi DA, Gornbein J. The Neuropsychiatric Inventory: comprehensive assessment of psychopathology in dementia. Neurology 1994; 44: 2308-14.

19 Folstein MF, Folstein SE, McHugh PR. 'Mini-mental state'. A practical method for grading the cognitive state of patients for the clinician. J Psychiatr Res 1975; 12: 189-98.

20 Mattis S. Dementia Rating Scale (DRS). Psychological Assessment Resources, 1988.

21 Dubois B, Slachevsky A, Litvan I, Pillon B. The FAB: a Frontal Assessment Battery at bedside. Neurology 2000; 55: 1621-6.

22 Kay SR, Fiszbein A, Opler LA. The positive and negative syndrome scale (PANSS) for schizophrenia. Schizophr Bull 1987; 13: 261-76.

23 May P, Dencker S, Hubbard J, Midha K, Liberman R. A systematic approach to treatment resistance in schizophrenic disorders. In Treatment Resistance in Schizophrenia (eds S Dencker \& F Kulhanel). Vieweg Verlag, 1988. 
24 Wechsler D. Echelle d'intelligence de Weschler pour Adultes (3rd edn). [Weschler Adult Intelligent Scale (3rd edn).] Edition du Centre de Psychologie Appliquée, 2000.

25 Solomon PR, Hirschoff A, Kelly B, Relin M, Brush M, DeVeaux RD, et al. A 7 minute neurocognitive screening battery highly sensitive to Alzheimer's disease. Arch Neurol 1998; 55: 349-55.

26 Rey A. Test de Copie et de Reproduction de Mémoire de Figures Géométriques Complexes. [The Rey Complex Figure Test and Recognition Trial.] Edition du Centre de Psychologie Appliquée, 1970.

27 Deloche G, Hannequin D. DO80. Edition du Centre de Psychologie Appliquée, 1997.

28 Van der Linden M, Coyette F, Poitrenaud J, Kalafat M, Calicis F, Wyns C, et al L'épreuve de rappel libre/rappel indicé à 16 items (RL/RI-16). In L'évaluation des Troubles de la Mémoire. Présentation de Quatre Tests de Mémoire Épisodique (avec leur Étalonnage) (eds M Van der Linden, S Adam, A Agniel C Baisset-Mouly, F Bardet). [The task of free recall/cued recall with 16 items. In The Assessment of Memory Disorders: Presentation of Four Tests of Episodic Memory (and their calibration).] Solal, 2004.

29 Cardebat D, Doyon B, Puel M, Goulet P, Joanette Y. Evocation lexicale formelle et sémantique chez des sujets normaux. Performances et dynamiques de production en fonction du sexe, de l'âge et du niveau d'étude. [Semantic and lexical formal evocation in normal subjects. Performance and dynamics of production related to sex, age, and education level.] Acta Neurol Belg 1990; 90: 207-17.

30 Hallstead W. Brain and Intelligence: A Quantitative Study of the Frontal Lobes. University of Chicago Press, 1947.

31 Stroop J. Studies of interference in serial verbal reaction. J Exp Psychol 1935 18: $643-61$.

32 Nelson HE. A modified card sorting test sensitive to frontal lobe defects. Cortex 1976; 12: 313-24.

33 Chow TW, Miller BL, Hayashi VN, Geschwind DH. Inheritance of frontotemporal dementia. Arch Neurol 1999; 56: 817-22.

34 Sikkink S, Rollinson S, Pickering-Brown SM. The genetics of frontotemporal lobar degeneration. Curr Opin Neurol 2007; 20: 693-8.

35 Riley B, Kendler KS. Molecular genetic studies of schizophrenia. Eur J Hum Genet 2006; 14: 669-80.

36 Momeni P, Detucci K, Straub RE, Weinberger DR, Davies P, Grafman J, et al. Progranulin (GRN) in two siblings of a Latino family and in other patients with Schizophrenia. Neurocase 2010: 1-7.
37 St Clair D. Copy number variation and schizophrenia. Schizophr Bull 2009; 35: 9-12.

38 Guilmatre A, Dubourg C, Mosca AL, Legallic S, Goldenberg A, Drouin-Garraud $V$, et al. Recurrent rearrangements in synaptic and neurodevelopmental genes and shared biologic pathways in schizophrenia autism, and mental retardation. Arch Gen Psychiatry 2009; 66: 947-56.

39 Meltzer HY. Suicidality in schizophrenia: a review of the evidence for risk factors and treatment options. Curr Psychiatry Rep 2002; 4: 279-83.

40 Palmer BA, Pankratz VS, Bostwick JM. The lifetime risk of suicide in schizophrenia: a reexamination. Arch Gen Psychiatry 2005; 62: 247-53.

41 Mendez MF, Shapira JS, Woods RJ, Licht EA, Saul RE. Psychotic symptoms in frontotemporal dementia: prevalence and review. Dement Geriatr Cogn Disord 2008; 25: 206-11.

42 Kurtz MM. Neurocognitive impairment across the lifespan in schizophrenia: an update. Schizophr Res 2005; 74: 15-26.

43 de Vries PJ, Honer WG, Kemp PM, McKenna PJ. Dementia as a complication of schizophrenia. J Neurol Neurosurg Psychiatry 2001; 70: 588-96.

44 Waddington JL, Youssef HA, Farrell MA, Toland J. Initial 'schizophrenia-like' psychosis in Pick's disease: case study with neuroimaging and neuropathology, and implications for frontotemporal dysfunction in schizophrenia. Schizophr Res 1995; 18: 79-82.

45 Vanderzeypen F, Bier JC, Genevrois C, Mendlewicz J, Lotstra F. Démence frontale ou 'démence précoce'? A propos de l'observation d'un trouble psychotique associé à une détérioration sévère. [Frontal dementia or dementia praecox? A case report of a psychotic disorder with a severe decline.] Encephale 2003; 29: 172-80.

46 Kitabayashi Y, Otakara C, Hirosawa R, Narumoto J, Fukui K. Frontotemporal dementia complicated with schizophrenia. Psychiatry Clin Neurosci 2005; 59: 749-50.

47 Velakoulis $D$, Walterfang $M$, Mocellin R, Pantelis C, McLean C. Frontotemporal dementia presenting as schizophrenia-like psychosis in young people: clinicopathological series and review of cases. Br J Psychiatry 2009; 194: 298-305.

48 Kendler KS, Gruenberg AM, Tsuang MT. Psychiatric illness in first-degree relatives of schizophrenic and surgical control patients. A family study using DSM-III criteria. Arch Gen Psychiatry 1985; 42: 770-9.

49 Baron M, Gruen R, Rainer JD, Kane J, Asnis L, Lord S. A family study of schizophrenic and normal control probands: implications for the spectrum concept of schizophrenia. Am J Psychiatry 1985; 142: 447-55. 